\title{
SEKOLAH BERASRAMA DI SULAWESI SELATAN
}

\author{
Faridah $^{1}$, Arismunandar ${ }^{2}$, Bernard $^{3}$ \\ 1,2,3Universitas Negeri Makassar \\ 1,2,3Jalan A.P. Pettarani \\ Email: faridah@unm.ac.id ${ }^{1}$, arismunandar@unm.ac.id², bernard@unm.ac.id ${ }^{3}$
}

\begin{abstract}
Abstrak:
Penelitian ini bertujuan untuk mendeskirpisikan pengelolaan sekolah berasrama di Sulawesi Selatan. Fokus penelitian ini adalah pengelolaan pendidikan akademik dan kehidupan keasramaan di sekolah berasrama. Penelitian dilakukan di 4 sekolah berasrama, 2 merupakan sekolah negeri, 1 sekolah swasta, dan 1 pesantren. Teknik pengumpulan data dilakukan melalui Focus Group Discussion (FGD), observasi dan studi dokumentasi. Hasil penelitian memperlihatkan bahwa sekolah berasrama dianggap lebih baik dibanding non-berasrama. Sekolah nonberasrama dianggap tidak bisa menghasilkan luaran yang mampu bersaing dengan siswa-siswa lain secara nasional dan global. Seleksi untuk masuk ke sekolah berasrama cukup ketat dan kompetitif, yang terdiri atas seleksi berkas, tes akademik, psikotes, dan wawancara. Ketatnya seleksi ini karena sekolah berasrama menetapkan standar akademik yang lebih tinggi dibandingkan sekolah lainnya. Hasil penelitian juga memperlihatkan bahwa keterlibatan orang tua dalam pendidikan anaknya di sekolah berasrama masih sangat terbatas. Umumnya masih dalam bentuk dukungan finansial dan sarana prasarana.
\end{abstract}

\begin{abstract}
:
This study aims to describe the management of boarding schools in South Sulawesi. The focus of this study is on academic aspect and students' life in boarding school. This study conducted in 4 boarding schools, 2 public schools, 1 private school, and 1 Islamic Boarding School (pesantren). Data collection techniques were conducted through Focus Group Discussion (FGD), observation and documentary study. The results show boarding schools are considered better than non-boarding. Non-boarding schools are believed unable to produce students who can compete with other students at the national and global level. The admission system for boarding school is quite strict and competitive, consisting of administrative selection, academic test, psychological test, and interview. This selection is very tight because boarding schools set higher academic standards than those of non-boarding schools. The results also show that parents' involvement in their children's education in boarding schools is still very limited. Their involvement is mostly in in the form of financial support for school facilities.
\end{abstract}

Kata kunci:

Sekolah Berasrama, Pengelolaan, Sulawesi Selatan

SEKOLAH berasrama di Indonesia menjadi fenomena yang tumbuh subur di Indonesia. Sekarang ini, pendidikan berasarama sudah mengalami perkembangan, mulai dari jenjang SMP, SMA, sampai pendidikan tinggi. Sekolah berasrama ini menjadi salah satu alternatif bagi masyarakat yang menginginkan pendidikan yang 
komprehensif dan holistik, yang tidak hanya fokus pada sistem pembelajaran di sekolah saja, namun termasuk juga melatih anak untuk hidup mandiri yang disertai dengan keterampilan sosial yang baik. Kehidupan keasramaan dianggap sebagai salah satu alternatif untuk melatih karakter anak agar menjadi lebih mandiri, disiplin, dan melatih kepekaan anak terhadap perbedaan-perbedaan yang ada diluar dirinya.

Undang-Undang Sistem Pendidikan Nasional No 19 tahun 2003, pasal 1 menyatakan bahwa pendidikan adalah usaha sadar dan terencana untuk menwujudkan suasana belajar dan proses pembelajaran yang efektif. Tujuan yang ingin dicapai adalah agar peserta didik mampu mengembangkan potensi dirinya. Potensi ini terdiri atas kekuatan spiritual keagamaan, kemampuan mengendalikan diri, kepribadian, ahlak mulia, dan keterampilan yang diperlukan bagi dirinya, masyarakat, dan bangsa (Presiden Republik Indonesia, 2003). Berdasarkan UndangUndang tersebut, salah satu pertanyaan penting yang perlu dijawab adalah sejauh mana pengelolaan pendidikan yang ada mampu mempersiapkan peserta didik untuk mengembangkan potensi dirinya. Hal ini tentu terkait juga dengan pendidikan berasrama yang sekarang sudah mulai berkembang di Indonesia.

Pendirian sekolah berasrama dilatarbelakangi oleh berbagai macam faktor. Di Amerika misalnya, sekolah berasrama didirikan untuk penduduk Indian untuk mendidik mereka menjadi warga Amerika (Graham, 2012). Di Cina, belakangan banyak didirikan sekolah berasrama untuk memperluas akses pendidikan kepada penduduk yang berada di daerah pinggiran Cina (Yue et al., 2014). Di Indonesia, fenomena yang terjadi adalah pendidikan berasrama dianggap lebih mampu menyediakan pendidikan berkualitas yang komprehensif. Sekolah berasrama yang muncul di Indonesia umumnya berbasis agama namun berbeda dengan pola pendidikan pesantren.

Di Indonesia, penelitian tentang sekolah berasrama ini sudah mulai dilakukan. Penelitian yang dilakukan umumnya pada konteks pesantren atau sekolah berasrama yang berbasis ajaran agama. El Kaifa (2012) misalnya melakukan penelitian tentang pola pendidikan Islam dalam sistem sekolah berasrama yang berbeda dengan pola pesantren. Hasil penelitiannya menunjukkan bahwa di SMP - SMA Sragen Bilingual, siswa tidak belajar tentang Islam dalam bentuk pengetahuan dan pembelajaran khusus seperti di pesantren. Nilai-nilai Islam dipelajari dengan cara dipraktikkan melalui pelaksanaan amalan wajib dan sunnah.

Studi lain dilakukan oleh Musiran (2012) mengenai Model Pembelajaran Al Islam dengan Sistem Boarding School, pada jenjang SMP. Al Islam yang dimaksud adalah adalah mata pelajaran yang menjadi ciri khusus di sekolah Muhammadiyah yang wajib diikuti oleh seluruh siswa, yang meliputi Al Qur'an, hadits, akidah, akhlaj, fikih dan sejarah Islam. Penelitian yang dilakukan fokus pada implementasi pembelajaran Islam yang dikaitkan dengan kepedulian orang tua, motivasi anak, perhatian kepala sekolah dan kesiapan guru.

Zakiyah, Hidayati, dan Setyawan (2010) melakukan penelitian tentang penyesuain diri siswa dan penundaan (prokrastinasi) akademik siswa di sekolah 
berasrama jenjang SMP. Hasil penelitian mereka memperlihatkan bahwa terdapat korelasi negative yang signifikan antara penyesuaian diri yang dilakukan oleh siswa dengan prokrastinasi akademik mereka. Semakin tinggi penyesuaian diri siswa, semakin rendah prokrastinasi akademik mereka (Zakiyah et al., 2010).

Hasil penelitian tentang sekolah berasrama memperlihatkan bahwa terdapat banyak aspek yang perlu diperhatikan pada sekolah berasrama yang membuatnya berbeda dengan sekolah non-berasrama. Hirshberg dan Sharp (2005) meneliti tentang dampak jangka panjang sekolah berasrama terhadap siswanya. Hasil penelitiannya memperlihatkan bahwa sekolah berasrama ternyata memberikan dampak, bukan hanya pada saat bersekolah, tetapi juga setelah mereka tamat, bahkan setelah 30 tahun mereka selesai sekolah. Terdapat responden yang menyatakan bahwa mereka bahkan tidak mengetahui bagaimana cara mendidikan anak di rumah, karena mereka tidak ketika usia sekolah mereka ditempatkan di asrama. Penelitian lain dilakukan oleh Hodges, Sheffield, dan Ralph (2013), mengenai asrama sebagai pengganti rumah, yang diistilahkan dengan "home away from home". Isu yang diteliti adalaha bagaimana sekolah berasrama bisa menciptakan suasana rumah dimana siswa merasa nyaman untuk tinggal dan bersekolah di sana. Dengan mempertimbangkan bahwa anak jauh dari keluarga, maka di sekolah berasrma diperlukan staf yang memiliki kemampuan untuk melakukan peran sebagai pengganti orang tua di sekolah berasrama.

Penelitian-penelitian yang disebutkan di atas memperlihatkan begitu kompleks aspek pengelolaan di sekolah berasrama. Jumlah sekolah berasrama yang semakin bertambah di Indonesia ternyata belum diikuti dengan kebijakan pengelolaan sekolah khususnya sekoah berasrama. Bahkan sekolah berasrama sebagai salah satu model pendidikan yang dianggap komprehensif belum diatur sedemikian rupa dalam kebijakan pendidikan nasional di Indonesia.

Penelitian ini berbeda dengan penelitian-penelitian yang telah dilakukan sebelumnya. Penelitian ini tidak dilakukan di satu sekolah saja, melainkan dilakukan di beberapa sekolah berasrama yang berbeda, negeri dan swasta, termasuk pesantren. Belum adanya standar yang berlaku secara nasional mengenai pendidikan berasrama terutama untuk jenjang SMP dan SMA, menjadi salah satu alasan mengapa penelitian ini dilakukan. Diharapkan hasil penelitian ini akan menemukan karakteristik pendidikan berasaram yang menjadi ruh dan spirit dari perkembangan pendidikan berasrama di Indonesia. Penelitian ini juga cukup komprehensif dan mencoba melihat bukan hanya kurikulum formalnya, tapi juga secara rinci kehidupan dan program keasramaan yang biasa disebut dengan kurikulum keasramaan. Diharapkan penelitian ini bisa memberikan gambaran yang lebih lengkap tentang sekolah berasrama, baik dari segi kurikulum formal dan keasramaan, maupun sistem pengelolaannya.

Pengelolaan sekolah di Indonesia dilaksanakan dengan mengacu pada standar nasional pendidikan yang diatur dalam PP Nomor 19 tahun 2005 tentang Standar Nasional Pendidikan. Berdasarkan peraturan tersebut, yang dimaksud dengan Standar Nasional Pendidikan adalah kriteria minimal tentang sistem pedidikan di 
seluruh wilayah hukum Negara Kesatuan Republik Indonesia (Presiden Republik Indonesia, 2005). Standar pengelolaan dan standar pembiayaan merupakan fondasi bagi standar lainnya, yaitu standar isi, standar proses, standar pendidikan dan tenaga kependidikan, standar sarana dan prasarana, dan standar penilaian, yang tujuannya untuk mencapai standar kompetensi lulusan yang telah ditetapkan. Lebih lanjut dijelaskan bahwa Standar kompetensi lulusan adalah kualifikasi kemampuan lulusan yang mencakup sikap, pengetahuan, dan keterampilan.

Dalam konteks sekolah berasrama, prinsip gotong royong dan kebersamaan merupakan salah satu landasan utama dalam membangun kehidupan keasramaan yang membelajarkan. Hal ini sejalan dengan paradigma pendidikan yang digunakan dalam penyusunan Renstra Kementerian Pendidikan dan Kebudayaan tahun 2015 2019. Salah satu diantara paradigm tersebut adalah Pendidikan yang Menghasilkan Pembelajar, Pendidikan yang Membentuk Karakter, dan Sekolah yang Menyenangkan (Kemendikbud, 2015). Dengan demikian, sekolah berasrama diharapkan mampu menghasilkan Pembelajar yang berkarakter, melalui proses pendidikan yang menyenangkan, termasuk program kehidupan keasramaan yang menjadi ciri khas sekolah berasrama.

Adapun tujuan dalam penelitian ini antara lain (1) Mengidentifikasi pengelolaan sekolah berasrama (2) Mengidentifikasi pengelolaan kegiatan kokurikuler, ekstra kurikuler, dalam kaitannya dengan program akadamik, non akademik, dan keasramaan, (3) Mengkaji pola kehidupan keasramaan dalam rangka mengembangkan potensi peserta didik yang merupakan tujuan pendidikan nasional, dan (4) Mengidentifikasi karakteristik utama dari pendidikan berasrama.

\section{METODE PENELITIAN}

Jenis penelitian ini adalah penelitian deskriptif. Karena penelitian ini merupakan studi awal, penelitian ini fokus pada pengelolaan sekolah berasrama secara umum yang dilakukan oleh sekolah berasrama yang menjadi target dalam penelitian ini. Penelitian ini dilakukan di 4 sekolah, yaitu satu Pesantren, dua sekolah berasrama berstatus negeri, dan satu sekolah berasrama berstatus swasta. Keempat sekolah ini merupakan sekolah berasrama dengan karakteristik yang unik. Pesantren dan sekolah berasrama berstatus swasta adalah sekolah berasrama yang dikelola oleh yayasan dan bercirikan Islam. Sedangkan 2 sekolah lainnya merupakan sekolah berasrama milik pemerintah. Salah satu dari sekolah berasrama tersebut merupakan sekolah negeri yang sistem akademiknya ditentukan oleh Yayasan. Pemilihan sekolah berasrama dengan jenis yang berbeda dilakukan secara sengaja untuk memperoleh gambaran mengenai pengelolaan sekolah berasrama dan konsep keasramaan yang ada di Sulawesi Selatan. Sumber data penelitian ini terdiri atas kepala sekolah, penanggung jawab asrama, kepala sekolah bagian kesiswaan, kepala sekolah bagian kurikulum, dan kepala program keasramaan. Sumber data ini dipilih karena tujuan penelitian ini adalah untuk melihat bagaimana konsep keasramaan dikembangkan dan dikelola oleh sekolah sebagai bagian yang terintegrasi dengan kurikulum 
nasional yang berlaku. Teknik pengumpulan data yang digunakan pada penelitian ini dilakukan melalui wawancara, FGD, observasi dan dokumentasi. Menurut Kambereli dan Dimitriadis (2008: 351), FDG merupakan "collective conversations or group interviews". Mereka juga menambahkan bahwa "focus groups, to a greater extent than observations and individual interviews, afford researchers access to the kind of social interactional dynamics that produce particular memories, positions, ideologies, practices, and desires among specific groups of people" (Kambereli \& Dimitriadis, 2008: 397). Data yang diperoleh direduksi dan dikelompokkan berdasarkan isu-isu yang muncul selama proses interview (Perakyla, 2008). Pertanyaan penelitian menjadi acuan utama sejauh mana data yang terkumpul menjawab pertanyaan penelitian yang ada. Dokumendokumen yang merupakan sumber data dalam penelitian ini dijadikan data pembanding dan pelengkap, terutama mengenai tata tertib sekolah. Dokumendokumen ini digunakan sebagai bagian dari sumber data untk memahami praktikpraktik yang terdapat di sekolah berasrama seperti yang dikatakan oleh Dean (2010) sebagai "a set of standards or norms of conduct bu which actual behavior can be judged, and which act as a kind of ideal towards which individuals and grous should strive.

\section{HASIL PENELITIAN DAN PEMBAHASAN}

\section{Atribut Sekolah Berasrama}

Hasil penelitian memperlihatkan bahwa sekolah berasrama dianggap lebih baik daripada sekoah non-berasrama karena sistem berasrama dianggap mampu untuk membantu siswa agar lebih fokus dalam belajar. Graham (2012) menuliskan bahwa sekolah berasrama "are generally understood to siginificantly impact the social development of their students". Setelah membandingkan 11 buku mengenai sekolah berasrama yang melihat dari sudut pandang sejarah, sosiologi, dan antropoli, sekolah berasrama pada saat ini dilihat sebagai "environment in which habits of language, behavior, and appearance are created and reinforced" (Graham, 2012). Hal ini sejalan dengan hasil penelitian yang memperlihatkan bagaimana tata tertib di sekolah berasrama mengatur pola kehidupan siswa agar sesuai dengan standar keasramaan yang telah ditetapkan. Lebih lanjut, Graham juga menyatakan bahwa standar perilaku dan identitas akan dibawa oleh siswa bahkan setelah mereka tamat. Dan pola kehidupan berasrama ini memfasilitasi munculnya identitas bersama atau "shared identity" yang dibangun dari lingkungan sekolah berasarama yang cenderung homogen.

Hasil diskusi kelompok dengan siswa memperlihatkan bahwa alasan mereka memilih untuk masuk ke sekolah berasrama adalah karena mendengar tentang prestasi sekolah, baik di bidang akademik maupun non akademik. Selain itu, sekolah berasrama menurut mereka mengajarkan mereka kemandirian, kebersamaan dan lingkungan asrama membuat mereka fokus belajar. Vigar-Ellis (2013) menuliskan dalam artikelnya bahwa beberapa alasan dalam pemilihan sekolah diantaranya: kurikulum pendidikan yang holistik (pengembangan dan kesejahteraan anak), faktor akademik, faktor sosial (karakteristik siswa dan orang tua), fasilitas sekolah reputasi 
sekolah terkait prestasi tertentu. Khusus untuk sekolah berasrama, orang tua memilih menyekolahkan anaknya di sekolah berasrama mungkin karena tradisi keluarga, lokasi sekolah yang jauh dari tempat tinggal, atau karena orang tua percaya bahwa sekolah berasrama memang lebih baik dibandingkan sekolah-sekolah lain yang tidak menggunakan sistem berasrama (Vigar-Ellis, 2013). Penelitian ini tidak memasukkan orang tua sebagai bagian dari informan. Namun mempertimbangkan budaya di Indonesia bahwa orang tua memegang peranan yang cukup dominan dalam menentukan sekolah anak, hasil penelitian memperlihatkan bahwa alasan pemilihan sekolah berasrama lebih kepada pertimbangan bahwa sekolah berasrama memiiki sistem pendidikan yang lebih baik dibandingkan sekolah non-berasrama.

El Kaifa (2012) menuliskan bahwa sekolah berasrama dapat dilihat dari aspek sosial, ekonomi, dan agama. Dari aspek sosial, sistem sekolah berasrama menyediakan lingkungan sosial ang cenderung homogen. Homogen dalam pengertian bahwa siswa masuk ke sekolah berasrama dengan satu tujuan yang sama yaitu menuntut ilmu dan mengejar cita-cita. Salah satu klaim yang dituliskannya adalah sekolah berasrama mengisolasi anak didik dari lingkungan sosial yang cenderung buruk (El Kaifa, 2012). Hasil FGD dengan beberapa siswa memperlihatkan persepsi ini. Bahwa berada di lingkungan sekolah berasrama membuat mereka fokus belajar dan tidak terpengaruh oleh lingkungan luar yang bisa berdampak buruk terhadap mereka. Dan hal ini juga didukung oleh kehidupan keagamaan yang disediakan di sekolah berasrama. Dari aspek agama, sekolah berasrama memberikan pendidikan yang dianggap seimbang antara fisik, jasmani, intelektual dan spiritual (El Kaifa, 2012). Dan hal ini bisa dilihat dari kegiatan-kegiatan ekstrakurikuler yang dilaksanakan di sekolah-sekolah berasrama. Setelah kegiatan belajar formal, siswa difasilitasi untuk mengikuti ekstra yang sifatnya wajib seperti pramuka, tahfidz Al Qur'an, dan pengayaan lainnya, serta kegiatan pilihan yang disesuaikan dengan minat dan bakat dan mereka.

Sekolah berasrama dipercaya memiliki peluang yang lebih baik untuk mengembangkan pendidikan yang berkualitas. Hasil penelitian ini memperlihatkan bahwa baik guru, siswa, dan pemerintah setempat percaya bahwa sekolah berasrama lebih baik dibandingkan sekolah non-berasrama. Namun Wickenden (2013) mengingatkan bahwa komunitas di asrama yang cenderung homogen, justru dapat menghasilkan siswa yang tidak memiliki pengetahuan dan kepekaan budaya yang diperlukan dimasa sekarang dan akan datang. Menurutnya, mayoritas sekolah berasrama menyiapkan siswa yang produktif namun terisolasi dalam lingkungan mereka sendiri. Salah satu rekomendasi yang Ia berikan terkait sekolah berasrama adalah perlunya menyiapkan siswa untuk menjadi warga negara dan warga dunia yang baik. Komunitas sekolah berasrama yang cenderung homogen, bisa menjadi kontra produktif untuk menghasilkan siswa yang mampu berinteraksi dengan orangorang dari latar belakang sosial, budaya, dan agama yang berbeda. Secara spesifik Wickenden (2013) menyarankan bahwa pendidikan perlu mengajarkan tentang agama dan budaya-budaya yang berbeda. Karena "a civil society is nit just about 
individual rights; it is about individual joining together to assume responsibility fro the quality of their society" (Wickenden, 2013). Sekolah berasrama memiliki peluang yang strategis untuk melakukan ini karena salah satu keunggulan sekolah berasrama adalah kebebasan yang mereka miliki untuk mendesain dan meredesain pendidikan yang terbaik menurut mereka.

\section{Seleksi Sekolah Berasrama}

Behagel, Clement, dan Gurgand (2015) melakukan penelitian mengenai dampak dari sekolah berasrama terhadap siswa yang berasal dari keluarga ekonomi ke bawah di Prancis. Mereka menemukan bahwa pada tahun-tahun pertama, tingkat "wellbeing" termasuk dalam kategori rendah. Menurut mereka, hal ini mungkin disebabkan karena pada tahun-tahun pertama siswa perlu beradaptasi dengan kehidupan asrama, jauh dari keluarga dan teman, serta memulai kehidupan dengan tingkat kedisiplinan dan standar pencapaian akademik yang tinggi. Mereka juga menemukan bahwa sistem sekolah berasrama sepertinya tidak cocok untuk anakanak yang tidak memiliki karakter yang kuat. Hasil studi mereka memperlihatkan bahkan setelah tahun kedua, anak-anak yang tidak cukup kuat untuk tinggal di asrama tidak memperlihatkan peningkatan dari tes yang diberikan.

Hasil penelitian di atas dapat digunakan untuk menjelaskan mengapa seleksi masuk di sekolah berasrama terlihat sangat ketat. Hasil penelitian ini memperlihatkan bahwa seleksi untuk masuk di sekolah berasrama terdiri atas seleksi akademik, tes tertulis, wawancara, dan psikotes. Standar akademik yang ditetapkan juga lebih tinggi dibandingkan sekolah non-berasrama. Khusus untuk wawancara, salah satu aspek penting yang digali adalah apakah keinginan untuk masuk ke sekolah berasrama merupakan keinginan siswa sendiri ataukah karena dorongan dari orang tuanya. Berdasarkan hasil FGD, hal ini penting untuk diketahui oleh pihak sekolah. Menurut mereka, siswa yang memilih sekolah berasrama berdasarkan keinginannya sendiri cenderung lebih siap untuk beradaptasi dengan kehidupan asrama dibandingkan dengan siswa yang masuk ke sekolah berasrama karena pilihan orang tuanya.

Sekolah berasrama juga memiliki cara tersendiri untuk membantu siswa beradaptasi dengan kehidupan keasramaan. Ada sekolah berasrama yang mewajbkan calon siswa untuk tinggal di sekolah berasrama selama 2 minggu sebagai bagian dari proses seleksi. Jika berdasarkan hasil pengamatan selama 2 minggu tersebut siswa bisa beradaptasi, maka dianggap siswa layak untuk diterima di sekolah berasrama tersebut. Hal ini memperlihatkan bahwa seleksi ketat dilakukan oleh sekolah berasrama karena menyadari bahwa hidup di sekolah berasarama merupakan tantangan tersendiri bagi seorang siswa. Karena selain untuk mencapai standar akademik yang ditentukan, siswa juga perlu beradaptasi dengan pola kehidupan berasarama. 


\section{Program dan Aktivitas di Sekolah Berasrama}

Perbedaan yang fundamental antara sekolah berasrama dan non-berasrama adalah adanya kehidupan dan program keasramaan di sekolah berasrama. Salah satu tantangan sekolah berasrama adalah bagaimana mendesain program dan praktik akademik yang unik untuk sekolah berasrama (Wickenden, 2013). Hasil penelitian ini memperlihatkan bagaimana sekolah-sekolah berasrama berupaya memaksimalkan program-program akademik dan non akademiknya yang menjadi ciri khas masingmasing sekolah berasrama, baik pesantren maupun non-pesantren. Kegiatan ini bervariasi mulai dari yang sifatnya akademik seperti pengayaan, remedial, persiapan olimpiade, sampai pada kegiatan keagamaan, olahraga, dan seni.

Aktivitas di sekolah berasrama secara umum sangat padat dibandingkan dengan sekolah berasrama. Hampir seluruh aktivitas dilakukan secara serentak dan berasrama. Aktivitas pagi dimulai jam 04.00 dimana seluruh siswa wajib bangun untuk bersiap-siap melaksanakan shalat subuh berjamaah dan aktivitas keagaam lain seperti tausiyah dan membaca Al Qur'an. Setelah itu siswa mandi secara bergantian, sarapan, dan bersiap-siap untuk mengikuti pembelajaran di sekolah.

Kegiatan akademik dimulai pada pukul 07.30 - 15.00. Setelah jadwal kegiatan akademik, siswa dapat beristirahat dan kembali melanjutkan aktivitas berdasarkan Kurikulum Keasramaan masing-masing sekolah. Kegiatan di sore hari biasanya diisi dengan kegiatan ekstrakurikuler, dimana siswa diperbolehkan untuk memilih kegiatan yang sesuai dengan minat dan bakatnya. Jenis-jenis kegiatan ekstra kurikuler ini cukup bervariasi dan berbeda untuk masing-masing sekolah. Namun secara umum kegiatan-kegiatan tersebut terdiri atas olahraga, seni, dan keagamaan.

Penelitian-penelitian tentang dampak sekolah berasrama terhadap perkembangan dan kemampuan siswa memperlihatkan temuan yang cukup bervariasi. Jenis sekolah, latar belakang sekolah berasrama, visi sekolah, merupakan hal-hal yang berpengaruh terhadap perkembangan siswa baik akademik maupun non-akademik (Behagel et al., (2015), Hodges et al., (2013), Hirshberg \& Sharp, (2005), Yue et al., (2014). Dan perkembangan ini, dipengaruhi oleh pengetahuan dan keterampilan yang dimiliki oleh pembina asrama, atau yang ditugaskan sebagai pengganti orang tua, atau pengawas asrama.

\section{Kompetensi Pembina/Pamong Asrama}

Salah satu tantangan dari pengelolaan sekolah berasrama adalah tersedianya pembina asrama yang memastikan kenyamanan kehidupan siswa selama berada di asrama. Struktur organisasi sekolah terkait pembina asrama ini cukup bervariasi. Hasil penelitian memperlihatkan pesantren yang memiliki jumlah pembina yang cukup memadai (rasio 1:40) yang salah satu tugas utamanya adalah berkomunikasi dengan orang tua siswa setiap 2 minggu. Sementara untuk sekolah lain, pembina asrama umumnya hanya dua, satu laki-laki, dan dan satu perempuan. Hasil penelitian memperlihatkan bahwa pembina asrama memegang peranan penting pada 
sekolah berasrama. Pembina asrama merupakan pengganti orang tua yang sekaligus bertugas memastikan bahwa siswa-siswa mengikuti tata tertib asrama.

Hodges dkk. (2013) menuliskan bahwa agar sekolah berasrama dapat membantu perkembangan siswa, para pembina asrama yang bertugas sebagai pengganti orang tua idealnya diberikan pelatihan yang sesuai tentang bagaimana menjadi pengganti orang tua di asrama. Pembina asrama memegang peranan yang sangat penting dalam perkembangan siswa di asrama. Karenanya, diperlukan pelatihan khusus untuk menjalanan peran yang sangat penting ini. Hal yang sama juga dituliskan oleh Yue dkk. (2014) dalam penelitian mereka tentang pengelolaan asrama di sekolah berasrama di daerah pinggiran (pedesaan) di Cina.

Menurut Hodges dkk. (2013) sekolah berasrama umumnya mempekerjakan guru sebagai bagian dari staf asrama. Dan sebagai bagian dari staf asrama, mereka bukan hanya berfungsi sebagai fasilitator dan penjamin keamanan, tapi mereka adalah "in loco parentis models" untuk siswa, orang tua bagi siswa. Mereka juga menyatakan bahwa lingkungan asrama, seperti layaknya lingkungan keluarga, merupakan tempat yang ideal pengembangan siswa dengan mengajarkan mereka berbagai macam keterampilan mulai dari menyeterika, memasak, dan kompetens sosial dan emosional seperti kemampuan komunikasi, pengendalian emosi, dan tanggung jawab. Sebagai tambahan, pembina asrama sebagai pengganti orang tua juga memerlukan pengetahuan mengenai standar kesehatan dan keamanan, kesehatan jasmani dan rohani, dan hukum perlindungan anak (Hodges et al., 2013).

Hal senada juga diungkapkan oleh Yue dkk. (2014). Di Cina, sekolah berasrama banyak didirikan di daearh-daerah pedesaan. Tingginya pertumbuhan sekolah berasrama berakibat pada perekrutan guru-guru sekolah berasrama yang minim pengalaman dalam mengelola siswa berasrama. Di Cina, staf sekolah yang ditugaskan untuk mengawasi siswa di asrama disebut dengan "shenghuo laoshi" atau "life teacher" (Yue et al., 2014: 524). Menurut aturan yang dikeluarkan oleh Menteri Pendidikan Cina, tugas mereka termasuk mengelola asrama, keselamatan siswa, logistik asrama, kesehatan mental, dan kesehatan fisik. Selain itu, dikatakan bahwa life teacher ini seharusnya dilatih tentang bagaimana mengajarkan kedisiplinan dan berkmomunikasi kepada siswa. Hasil penelitian mereka memperlihatkan bahwa life teacher ini tidak memperoleh pelatihan yang cukup untuk melaksanakan tugas yang menjadi tanggung jawab mereka. Hal ini sejalan dengan artikel yang ditulis oleh Hodges dkk. (2013), bahwa pembina asrama tidak memiliki akses untuk memperoleh pelatihan yang cukup untuk melaksanakan tugas mereka sebagai pengganti orang tua di sekolah berasrama, terutama untuk pengembangan siswa.

Wickenden (2013) berpendapat bahwa seluruh orang dewasa yang bekerja di sekolah berasrama memegang peranan penting dalam kehidupan non-akademik sekolah. Bagaimanapun, staf yang belum memiliki pengalaman yang cukup seharusnya tidak diberi tanggung jawab untuk melakukan peran sebagai pembina asrama. Menurutnya salah satu elemen penting bagi seorang pembina asrama adalah 
tinggal bersama siswa di asrama dan bagaimana dia mampu berinteraksi dengan siswa di luar kelas.

Hasil penelitian ini menunjukkan hal yang relatif mirip. Sekolah berasrama memiliki otonomi yang sangat luas dalam mendesain kurikulum keasramaan, termasuk tata tertib, dan strutur organisasi sekolah. Sayangnya, pemerintah dalam hal ini Kementerian Pendidikan Nasional belum memiliki kebijakan yang jelas mengenai standar sekolah berasrama, termasuk standar kompetensi yang harus dimiliki oleh guru sekaligus staf di sekolah berasrama. Data penelitian memperlihatkan bahwa pelatihan-pelatihan yang diberikan kepada guru dan sekalgus pengelola asrama umumnya fokus pada aspek akademik, yaitu kompetensi profesional dan kompetensi pedagogik. Pelatihan-pelatihan tentang bagaimana menjadi pengganti orang tua di sekolah belum terungkap dalam penelitian ini. Permasalahan-permasalahan yang dihadapi oleh siswa umumnya ditangani oleh guru Bimbingan Konseling, bukan oleh pembina asrama. Hal ini menjadi catatan tersendiri, mengingat asrama merupakan rumah bagi siswa seperti yang disebutkan oleh Hodges dkk. (2013) sebagai "a home away from home".

\section{Kelebihan dan Kelemahan Sekolah Berasrama: Perspektif Siswa}

Salah satu hal penting dalam penelitian tentang sekolah berasrama adalah mendengarkan pengalaman dan perasaan siswa yang bersekolah di sekolah berasrama. Hal-hal positif yang dirasakan oleh siswa adalah sekolah berasrama membuat mereka menjadi lebih mandiri, memiliki rasa persaudaraan, bisa lebih fokus belajar, dan terhindar dari lingkungan luar yang menurut mereka bisa memberikan dampak negatif. Mereka juga senang dengan keteraturan yang ada, termasuk kebebasan untuk memilih kegiatan-kegiatan ekstrakurikuler yang disediakan oleh sekolah.

Kelemahan yang mereka rasakan adalah siswa merasa jauh dari pantauan orang tua, jadwal belajar yang telalu padat, dan peraturan yang terkadang terasa terlalu ketat. Seperti yang telah dipaparkan sebelumnya, siswa sekolah berasrama kadang berasal dari daerah yang jauh dari lokasi. Akibatnya, beberapa siswa hanya dapat bertemu dengan orang tuanya pada saat libur panjang, berarti sekali dalam 6 bulan. Selain itu, perbedaan pola belajar yang berbeda dengan sekolah sebelumnya membuat mereka merasa agak terkekang, termasuk dengan aturan-aturan keasramaan yang oleh beberapa siswa membatasi waktu mereka untuk bermain, dan jauh dari pusat keramaian.

Hasil penelitian dari Hirshberg dan Sharp (2005) tentang dampak jangka panjang dari sekolah berasrama diantaranya menyebutkan bahwa berada jauh dari keluarga membuat mereka kehilangan role model dalam parenting style. Selain itu, mereka juga merasa asing dengan kebiasaan-kebiasaan keluarga. Ketika tinggal di asrama, mereka wajib mengikuti peraturan dan tata tertib yang ditetapkan oleh sekolah berasrama. Hal ini juga dirasakan oleh siswa yang terlibat dalam penelitian 
ini. Mereka merasa kesulitan untuk berdaptasi dengan kehidupan di luar asrama, bahkan kesulitan untuk berinteraksi kembali dengan teman-temannya terdahulu sebelum mereka masuk di sekolah berasrama. Wickenden (2013) telah menuliskan hal ini sebagai salah satu tantangan bagi sekolah berasrama. Bahwa sistem sekolah berasrama dapat menghasilkan siswa dengan komunitas yang ekslusif yang tidak memiliki wawasan dan keterampilan yang cukup untuk beradaptasi dengan lingkungan luar yang berbeda dengan kehidupan mereka di sekolah berasrama.

\section{SIMPULAN}

Sekolah berasrama memiliki karakteristik yang berbeda dengan sekolah non berasrama, mulai dari seleksi yang dilakukan, proses pembelajaran, dan kegiatankegiatannya. Sekolah berasrama memiliki karakter yang secara tidak langung menciptakan komunitas warga sekolah yang berbeda dengan kondisi masyarakat di luar sekolah. Untuk mencegah timbulnya kultur ekslusif, sekolah berasrama perlu lebih memperkenalkan tentang kebiasaan-kebiasaan lain yang berbeda dengan sekolah untuk mempersiapkan agar siswa tidak kaget dan siap menerima perbedaan budaya yang akan mereka temukan di luar asrama.

Sekolah berasrama memiliki tanggung jawab lebih karena sistem keasramaan yang memerlukan pembina asrama berperan sebagai pengganti orang tua di asrama. Pelatihan yang sifatnya spesifik diperlukan untuk memberikan pengetahuan dan keterampilan kepada pembina asrama mengenai perkembangan psikologi anak, keterampilan komunikasi, kesehatan, termasuk pelatihan tentang keselamatan dan perlindungan anak.

Penelitian ini sifatnya kualitatif dan lebih banyak menggali informasi deskriptif tentang sekolah berasrama. Penelitian selanjutnya perlu dilakukan yang lebih menggali tentang perspektif siswa dan guru dengan menggunakan instrument kuantitatif yang bisa digunakan sebagai dasar untuk melakukan penelitian pengembangan model sekolah berasrama.

\section{DAFTAR PUSTAKA}

Behagel, L., Clement, D. C., \& Gurgand, M. (2015). Ready for Boarding? The Effects of A Boarding School for Disadvantaged Students. American Economic Journal: Applied Economics, 9(1), 140-164. Retrieved from https://www.povertyactionlab.org/sites/default/files/publications/236_Ready-forboarding_Jan2017.pdf

Dean, M. (2010). Governmentality: Power and Rule in Modern Society (2nd ed.). UK: University of Newcastle.

El Kaifa, K. (2012). Pola Pendidikan Islam Sistem Boarding School di SMP-SMA Sragen Bilingual Boarding School, Gemolong, Sragen Tahun 2012/2013, 1-20. Retrieved from http://eprints.ums.ac.id/25642/15/NASKAH_PUBLIKASI.pdf 
Graham, A. G. (2012). The Power of Boarding Schools: A Historiographical Review. America Educational History Journal, 39(2), 462-481. Retrieved from https://www.highbeam.com/doc/1G1-305660543.html

Hirshberg, D., \& Sharp, S. (2005). Thirty Years Later: The Long-Term Effect of Boarding Schools on Alaska Natives and Their Communities. Alaska. Retrieved from $\mathrm{http} / / /$ citeseerx.ist.psu.edu/viewdoc/download?doi=10.1.1.587.2754\&rep=rep1\&type= pdf

Hodges, J., Sheffield, J., \& Ralph, A. (2013). Home Away from Home? Boarding in Australian Schools. Australian Journal of Eduction, 57(1), 32-47. Retrieved from https://www.researchgate.net/profile/Julie_Hodges/publication/258124091_Home_aw ay_from_home_Boarding_in_Australian_schools/links/571d8a0808ae6eb94d0e52cc/H ome-away-from-home-Boarding-in-Australian-schools.pdf

Kambereli, G., \& Dimitriadis, G. (2008). Focus Groups: Strategic Articulations of Pedagogy, Politics, and Inquiry. Thousand Oaks: SAGE Publications.

Kemendikbud. (2015). Rencana Strategis Kementerian Pendidikan dan Kebudayaan 20152019. Jakarta.

Musiran, M. (2012). Model Pembelajaran Al-Islam dengan Sistem Boarding School. Institut Agama Islam Negeri (IAIN) Walisongo Semarang. Retrieved from http://eprints.walisongo.ac.id/74/1/Musiran_Tesis_Sinopsis.pdf

Perakyla, A. (2008). Collecting and Interpreting Qualitative Materials. (N. K. Denzin \& Y. S. Lincoln, Eds.). Thousand Oaks, CA: SAGE Publications, Inc.

Presiden Republik Indonesia. Undang-Undang tentang Sistem Pendidikan Nasional Tahun 2003 (2003). Jakarta.

Presiden Republik Indonesia. Peraturan Pemerintah Nomor 19 tahun 2005 tentang Standar Nasional Pendidikan (2005). Jakarta.

Vigar-Ellis, D. (2013). Boys' Boarding School Management: Understanding The Choice Criteria of Parents. South African Journal of Education, 33(1), 447-461. Retrieved from https://www.ajol.info/index.php/saje/article/viewFile/85006/74977

Wickenden, J. W. (2013). Creating The Future: New Challenges for Boarding Schools. Wickenden Associates. Retrieved from http://www.wickenden.com/cms/wpcontent/uploads/2013/02/Creating-the-Future.pdf

Yue, A., Shi, Y., Chang, F., Yang, C., Wang, H., Yi, H., ... Rozelle, S. (2014). Dormitory Management and Boarding Students in China's Rural Primary Schools. China Agricultural Economic Review, 6(2), 523-550. Retrieved from https://www.researchgate.net/profile/Scott_Rozelle/publication/265102916_Dormitory _Management_and_Boarding_Students_in_China\%27s_Rural_Elementary_Schools/li nks/5432af2e0cf225bddcc7c582/Dormitory-Management-and-Boarding-Students-inChinas-Rural-Elementary-

Zakiyah, N., Hidayati, F. N. R., \& Setyawan, I. (2010). Hubungan antara Penyesuaian Diri dengan Prokrastinasi Akademik Siswa Sekolah Berasrama SMPN 3 Peterongan Jombang. Jurnal Psikologi Undip, 8(2), 156 - 167. Retrieved from https://ejournal.undip.ac.id/index.php/psikologi/article/download/2960/2646 